\title{
LEITURA, LITERALIDADE E LITERATURA INFANTIL: REFLEXÕES NECESSÁRIAS À BIBLIOTECONOMIA
}

\author{
READING, LITERALITY AND CHILDREN'S \\ LITERATURE: REFLECTIONS REQUIRED FOR \\ LIBRARIANSHIP
}

Mariana de Souza Alvesa

\begin{abstract}
RESUMO
Introdução: Trata dos aspectos teóricos da literatura infantil e da importância do conhecimento dessa temática pelos (as) bibliotecários (as) para a sua atuação. Objetivo: Busca compreender e refletir como se configura a leitura literária infantil em termos teóricos e qual o significado e a importância da linguagem literária para a criança. Metodologia: Utiliza a pesquisa exploratória e bibliográfica para discutir a temática a partir da produção científica e literária de autores (as) e críticos (as), sobretudo no contexto brasileiro entre os fins da década de 1970 até fins dos anos 2000. Resultados: Apresenta um resgate teórico dos estudos sobre leitura, literalidade e literatura infantil demonstrando como esses conceitos se relacionam entre si e ressaltando que tanto a leitura quanto a literatura são elementos permeados de contextos ideológicos, sociais e históricos de produção. Conclusões: Conclui que a literatura infantil opera no desenvolvimento do imaginário e da autonomia da criança e que o (a) bibliotecário pode contribuir com a emancipação do (a) leitor (a) por meio da mediação de leitura.
\end{abstract}

Descritores: Leitura. Literatura. Literalidade. Literatura Infantil. Biblioteconomia

\section{INTRODUÇÃO}

Sabemos que o profissional bibliotecário e a profissional bibliotecária possuem uma amplitude de áreas em que podem atuar, incluindo as diversas tipologias de bibliotecas, as quais podemos destacar as bibliotecas públicas e escolares, sobretudo nesses espaços, a atuação do bibliotecário (a) educador (a) é fulcral para a formação de leitores, no que tange principalmente a indicação

\footnotetext{
a Doutoranda pelo Programa de Pós-Graduação em Ciência da Informação da Universidade Federal de Pernambuco (PPGCI-UFPE). E-mail: mdsa24@gmail.com
} 
e sugestões de leituras que vão formar o repertório dos leitores e leitoras.

Nesse sentido, a compreensão acerca da importância da leitura e do caráter polissêmico da literatura são elementos fundamentais na formação destes e destas profissionais. Mas será que o (a) bibliotecário (a) está preparado (a) para lidar com essas questões? Será que sua formação abarca essas discussões? A responsabilidade social inerente a profissão do (a) bibliotecário (a) no que respeita a formação de leitores, é de suma importância no contexto da Biblioteconomia e por isso, as discussões e reflexões acerca da formação e da reestruturação da matriz curricular dos cursos é indispensável (BORTOLIN; SILVA, 2015).

Por isso, este texto tem como objetivo refletir e compreender como se configura a leitura literária infantil do ponto de vista teórico e qual o significado e a importância da linguagem literária para a criança. Em outras palavras visa apresentar a leitura e suas diferentes concepções conceituais; discutir o conceito de literatura e literalidade; apresentar as origens e conceitos da literatura para infância e fazer algumas considerações a respeito da inter-relação entre leitura, literatura e literatura infantil.

Trata-se de uma pesquisa exploratória e bibliográfica que buscou discutir a temática a partir da produção científica e literária de autores (as) e críticos (as), sobretudo no contexto brasileiro. A literatura científica compreendeu o recorte temporal entre os fins da década de 1970 até meados dos anos 2000, em sua maioria, contemplando os estudos iniciais a respeito da temática por meio de teóricas e críticas brasileiras que foram e ainda são essenciais para a compreensão do tema.

Ao final, tecemos algumas considerações sobre a leitura literária infantil bem como algumas de suas características retomando os autores citados e incluindo outros com o fim de esclarecer as concepções teóricas norteadoras desse gênero literário endereçado às crianças.

\section{LEITURA E SUAS MÚLTIPLAS CONCEPÇÕES}

Uma palavra, um desenho no muro, um boneco de barro, um parque, uma música, uma peleja, possibilitam diversos tipos de leitura. Quando se trata de 
falar sobre leitura, muitas facetas se manifestam neste ato de compreender e observar o mundo. Dessa forma, o ato de ler está vinculado a diferentes modos de ver e sentir a natureza, a vida e as pessoas.

Partimos de um entendimento de que a leitura compreende não apenas um texto escrito, mas também outros tipos de expressões do fazer humano (ALMEIDA JÚNIOR, 2009). Da mesma forma, não denota apenas a decodificação mecânica de um texto, mas envolve componentes do nosso sistema sensorial, emocional, fisiológico e cultural (MARTINS, 1982).

Levando em consideração os três elementos básicos da leitura: o sujeito (leitor), o objeto (texto) e as condições sociais de sua produção, Paulo Freire (2011) desenvolve sua acepção sobre leitura e escrita partindo do pressuposto de que a efetiva leitura ocorre por meio da compreensão do contexto numa relação dinâmica que vincula linguagem e realidade. Dessa forma, a leitura crítica implica nas relações entre texto e contexto.

De modo mais específico e adentrando em uma perspectiva discursiva da leitura, mas mantendo o diálogo com os autores e autoras anteriores, a linguista Eni Orlandi (1998) acredita que o que delimita o sentido do conceito de leitura, numa perspectiva discursiva é a ideia de interpretação e de compreensão.

Por isso, a autora concebe a leitura sob alguns princípios. São eles, a ideia de que a leitura, tanto quanto a escrita, fazem parte do processo de instauração do (s) sentidos (s); o sujeito-leitor tem suas especificidades e sua história; tanto o sujeito quanto os sentidos são determinados histórica e ideologicamente; existem múltiplos e variados modos de leitura, e a noção de que a nossa vida intelectual está intimamente relacionada aos modos e efeitos de leitura de cada época e segmento social (ORLANDI, 1998).

Dessa forma, a legibilidade de um texto "é a natureza da relação que alguém estabelece com o texto" (ORLANDI, 1998, p. 9). Defende Orlandi que a legibilidade, longe de ser algo absoluto ou ligado à essência do texto, está relacionada a níveis ou condições de compreensões que dependem de fatores históricos. Em suas palavras: "a leitura, portanto, não é uma questão de tudo ou nada, é uma questão de natureza, de condições, de modos de relação, de trabalho, de produção de sentidos, em uma palavra: de historicidade" (ORLANDI, 
1998, p. 9).

Todavia, não é só esta relação que indica a dinâmica do processo de leitura, os distintos modos de ler são outros componentes importantes, cujas variações dependem do contexto e das condições de produção em que se dão.

Considerando a relação autor/texto/leitor, a autora destaca três máximas: não existe autor onipotente que controle todos os modos de compreensão e significação do texto; da mesma forma não existe leitor onisciente que compreenda todos os jogos de sentido que uma leitura pode promover; não existe texto transparente que diga por si toda ou apenas uma significação.

Assim, o historiador francês Roger Chartier (1998) assegura que a leitura possui uma relação dialética com o (a) leitor (a), na qual o (a) segundo (a) interage com o (a) primeiro (a) de forma dupla: de um lado sob um viés apropriativo e inventivo, capaz de produzir significados e de outro por meio de práticas de leitura adquiridas socialmente mediante convenções e hábitos históricos. Assim, conforme salienta Michèle Petit (2008, p. 26) "na realidade, os leitores apropriam-se dos textos, Ihes dão outro significado, mudam o sentido, interpretam à sua maneira, introduzindo seus desejos entre as linhas: é toda a alquimia da recepção".

A complexidade desses elementos faz com que concluamos que existem determinações distintas que influenciam no processo de leitura e legibilidade de um texto, seja de natureza histórica, social, linguística ou ideológica e que todas elas se inscrevem na ideia de produção da leitura. A polissemia de sentidos, finaliza Orlandi, é permeada por um processo histórico, por isso "há uma determinação histórica que faz com que só alguns sentidos sejam 'lidos' e outros não" (ORLANDI, 1998, p.12).

No que tange ao âmbito da leitura infantil, Zilberman e Magalhães (1987, p.13) citando Peukert (1976) afirmam que: o ler "relaciona-se com o desenvolvimento lingüístico da criança, com a formação da compreensão do fictício, com a fruição específica da fantasia infantil, com a credulidade da história e a aquisição de saber".

A importância do (a) leitor (a), também é apontada por Zilberman e Magalhães (1987) quando concordam que o (a) leitor (a) é uma figura 
exponencial na leitura literária, pois é a sua percepção do fenômeno estético que organiza, atualiza e revitaliza a narrativa. Tal recepção envolve tanto 0 preenchimento das lacunas do texto por meio da imaginação, como a reconfiguração das informações sob uma perspectiva atual e conforme 0 repertório de cada leitor (a).

Dessa maneira, tendo como foco a leitura literária infantil e a concepção comum dos (as) autores (as) citados (as) nesta seção, é possível entender que a interpretação e compreensão que a criança faz da realidade é auxiliada pela relação dinâmica entre contexto e linguagem e que quando essa linguagem se dá por meio da leitura, ela é potencializada, porque propicia uma experienciação simbólica no plano imaginário e sua consequente correspondência no plano real.

\section{ENTRE A LITERATURA E A LITERALIDADE}

O debate sobre o que é literatura ou que é literário é uma discussão que deve ser travada com cautela, já que o tema demanda um conceito que não possui uma definição estanque ou consensual. A crítica literária paulista Marisa Lajolo em seu livro O que é literatura é enfática quando afirma que "não existe uma resposta correta, porque cada tempo, cada grupo social tem sua resposta, sua definição para literatura". E afirma mais: "desconfio [...] que a literatura continuará a ser o que é para cada um, independente do que outros digam que ela é" (LAJOLO, 1982, p. 25).

Dessa maneira, o conceito de literatura, além de envolver uma subjetividade temporal, inclui uma subjetividade individual e assim se configura porque lhe é inerente a capacidade de ser multifacetada e polissêmica. Ou seja, a literatura traz em si mesma a amplitude de significados e possibilidades quando brinca com a ambiguidade e significação da linguagem. Diante disso, como distinguir uma obra literária de uma obra não literária? O que garante a literalidade de uma obra? A literalidade de um texto é inerente a ele?

Para Márcia Abreu (2006) a literalidade não está apenas no texto, mas na forma como ele é lido. A escritora, embora considere que o conceito de literatura é um constructo histórico cultural, afirma que ele não é visto dessa forma pela Crítica Literária e assinala que "por trás da definição de literatura está um ato de 
seleção e exclusão, cujo objetivo é separar alguns textos, escritos por alguns autores do conjunto de textos em circulação" (ABREU, 2006, p.39).

No âmbito da literatura infantil, afirma Peter Hunt (2010, p.89): "de fato, ater-se a um cânone e a uma "cultura" significa priorizar um grupo e um discurso e, com isso, alienar o resto (nesse caso, a literatura infantil)".

Abreu argumenta que, ao contrário do que afirmam os críticos literários sobre a adoção da literalidade como critério de seleção de textos, o que de fato se percebe é que, na maioria das vezes, não são os critérios linguísticos, textuais ou estéticos imanentes aos textos que guiam essa seleção de textos e autores, mas entram em cena também questões externas de ordem político-sociais e valorativas, tais como reputação e prestígio do autor/a e editora (ABREU, 2006).

Dessa forma, dois textos podem ser bem semelhantes em termos de literalidade e ainda assim, um pode ser considerado literário e outro não. Por isso, não é possível garantir a seleção dos textos "literários" apenas pela definição de gêneros, procedimentos linguísticos ou utilização de figuras de linguagem, pois para que uma obra seja considerada "Grande Literatura" é necessário que ela seja chancelada pelas chamadas "instâncias de legitimação". Assim "o que torna um texto literário não são suas características internas, e sim o espaço que the é destinado pelas críticas e, sobretudo, pela escola no conjunto dos bens simbólicos" (ABREU, 2006, p.40).

Assim, a definição de literatura não é algo concreto e universal, mas sim algo cultural e histórico, pois cada grupo social possui critérios próprios conforme sua cultura para analisar e avaliar suas manifestações artísticas estando ela no âmbito da literatura, música, teatro, artes plásticas entre outras. Por isso, não é sensato que o julgamento de textos seja feito por meio de um único critério - que geralmente é o critério da erudição - sem levar em consideração o contexto de valores em que essas obras foram criadas (ABREU, 2006).

Agindo dessa forma, contribui-se para o alijamento de outras produções literárias que, embora sejam igualmente legitimas, não possuem espaço de aceitação pela elite intelectual. O que deve se considerar, portanto é que tanto a produção literária erudita como a produção literária popular ou infantil, por exemplo, são formas diferentes de se fazer literatura composta por distintos 
grupos culturais em períodos diferentes (ABREU, 2006).

Coelho (2000) sustenta que dificilmente a literatura poderá ser definida de forma exata, porquanto cada época entendeu e criou literatura a seu modo. Assim conhecer a singularidade da literatura produzida a cada momento da história da humanidade, significa conhecer os ideais e valores ou desvalores pelos quais cada sociedade se fundamentou.

Da mesma forma que a opinião de um crítico literário denotará uma possível leitura da obra, mas não a única, a correta ou a autorizada leitura (ABREU, 2006). Reiterando essa questão, Yunes e Pondé (1998, p. 142) compreendem que "em nenhum momento, um crítico, por mais atualizado que seja, está legitimado para prescrever o modo de interpretação de uma obra literária como se apenas ele detivesse o caminho correto de abordagem".

Ademais, vão mais além quando conferem ao leitor o papel intransferível e legítimo de crítico: "portanto o que cabe é o exame atento da obra poética pelo leitor" para a partir das suas experiências deixar-se tocar pelo questionamento, realizando uma inevitável análise da obra daquilo que o surpreende. Assim, "a crítica é, pois, função do leitor em planos e níveis diversos, espreguiçando-se na poltrona, em meio ao ruído da redação do jornal ou no exercício da cátedra universitária" (YUNES; PONDÉ, 1998 p.143).

Nesse sentido, diz Abreu (2006) que ampliar os saberes sobre a cultura local e a cultura de outros povos, constitui um dos motivos para desfrutar da literatura. Tal aquisição pode ser feita tanto por meio da literatura erudita como por meio de textos não canonizados, já que ambas leituras poderão contribuir para a reflexão da cultura e das variadas formas de expressão que a literatura pode se manifestar.

Abreu finaliza constando que: "Não há obras boas e ruins em definitivo. $O$ que há são escolhas e o poder daqueles que as fazem. Literatura não é apenas uma questão de gosto: é uma questão política" (ABREU, 2006, p.112). Ou, concordando com Yunes e Pondé (1998, p.44), acreditamos que "se pode considerar como literatura qualquer texto que tenha a tensão da arte, esteja publicado ou não".

Para Coelho (2000) o que agrega maior ou menor valor literário à obra é 
uma junção de elementos que inclui além da intencionalidade (autor, editor) e sua concretização; a consciência de mundo que subjaz implícito na intenção da obra e a natureza do discurso literário, cuja linguagem encorpa a consciência de mundo.

Da mesma forma, Peter Hunt também acredita que o terreno da crítica literária é cheio de ambivalências e que os valores que se atribuem a uma obra literária pertencem a um sistema cultural, camuflando a ideia de que "há um sistema de valor intrínseco que estabelece Camões acima de todos os demais, e não de um sistema de poder/cultura que julga conveniente assim situá-lo" (HUNT, 2010, p. 20).

Por isso, pontua o autor, a única questão real é de status, e essa é uma questão de poder que sob a ideia de literalidade "pode ser vista como uma cortina de fumaça colocada pelo sistema para evitar expor a simples verdade de que algo é bom porque nós, autoeleitos, assim o dizemos" (HUNT, 2010, p.82). Assim, não existe motivo para os livros para criança ficarem de fora do cânone respeitável ou não serem estudados com o mesmo rigor que os textos para adultos (HUNT, 2010).

Desse modo, partindo do pressuposto de que a definição de literatura está imbuída de questões outras e não apenas a literalidade do texto e que retrata um determinado período histórico dentro de uma certa cultura, iremos expor algumas considerações sobre o que é literatura e os efeitos que ela proporciona enquanto arte, sob o olhar de alguns (mas) escritores (as) e teóricos (as).

Para Lajolo (1982), é importante antes de tudo compreender que a obra literária é um objeto social, pois é composta pelo escritor e pelo leitor e é esse intercâmbio social que promove a interação estética entre quem escreve e quem lê, fazendo cumprir a natureza social da literatura.

Seja como um conjunto de obras exemplares ou significativas para uma determinada comunidade, ou como o uso da palavra para criar mundos correspondendo a um uso específico da palavra:

[...] a literatura é essencialmente um produto, como um livro ou um filme, um arquivo ou uma fala, um jogo narrativo ou um modo de viver. Algo que é possível identificar com base em traços característicos, formatos específicos ou elementos reconhecidos pela sua origem ou tradição literária. (COSSON, 2014, p. 23). 
Candido (2012, p. 23) denomina literatura, da maneira mais ampla possível, como:

[...] todas as criações de toque poético, ficcional ou dramático em todos os níveis de uma sociedade, em todos os tipos de cultura, desde o que chamamos folclore, lenda, até as formas mais complexas e difíceis da produção escrita das grandes civilizações.

Para Lima (2012, p. 43) "a literatura é uma vasta metáfora da qual se vale o ser humano para interrogar, recriar, revelar, interpretar, compreender e narrar a sua história, que é a história da humanidade". Assim para o autor, a tragédia, a epopeia, o soneto, o haicai, o romance, o conto:

[...] são formas em cujos conteúdos as sociedades humanas indagam sobre si próprias através de um texto, oral ou escrito, que não só Ihes proporciona o prazer lúdico-estético, como expressa os elementos mais característicos, mais longínquos de suas antropologias (LIMA, 2012, p. 41).

O papel contraditório, portanto, humanizador da literatura, conforme explicitada por Candido (2012), revela sua relação dialética de confirmação e negação; proposta e denúncia; apoio e combate e que desta forma delineia a personalidade da pessoa. No entanto, ela não ocorre conforme os padrões, mas "segundo a força indiscriminada e poderosa da própria realidade". A obra literária, pois, pode ser fator de perturbação e de risco, de virtude ou libertação. "Ela não corrompe nem edifica, portanto; mas, trazendo livremente em si o que chamamos o bem e o que chamamos o mal, humaniza em sentido profundo, porque faz viver" (CANDIDO, 2012, p. 25, grifo do autor).

Assim, concordamos também com Rosenfeld (1976, p. 54), quando apresenta o discurso literário como um discurso emocional, imaginativo, ambíguo, irônico, paradoxal, alusivo, metafórico e simbólico que se difere do discurso científico (referencial, racional, instrumental) por manter uma estrutura de significados autônomos, cujo objetivo é a comunicação intensa e vivida da experiência que nele se organizou.

Por isso, acreditamos que a literatura, assim como elencaram alguns autores e autoras, corresponde a um uso específico da palavra, um uso diferenciado da linguagem que busca por meio de uma narrativa oral, escrita ou imagética resgatar, recriar ou interrogar a humanidade que nos é indissociável. Essa experienciação da história do outro, nos permite viver um mundo diferente, 
nos causando uma sensação de empatia.

A essa experiência vivida ou esse sonho que nos é apresentado pela literatura, resta-nos contemplação crítica e apreciação estética das condições e possibilidades que são possíveis na existência humana. Da mesma maneira, a literatura cria um espaço de interação e subjetividade que por meio da fantasia ou da realidade leva-nos a liberdade de pensamento, a especulação de possibilidades, antes não pensadas.

Por fim, conforme iniciamos o texto, "ao tratar de literatura e de valor estético, estamos em terreno movediço e variável e não em terras firmes e estáveis" (ABREU, 2006, p. 58), a subjetividade, temporalidade e polissemia a que dela deriva, faz com que surjam diversas possibilidades de definição do termo. Por isso, devido ser uma manifestação artística e permitir distintas possibilidades de sentir, trouxemos além das questões que envolvem os critérios de julgamento de uma obra literária, algumas compreensões de escritores e escritoras, pois em que pese ser um conceito instável e que possa ter valoração que envolva questões outras, não deixa de ser sentido e apreciado por cada um.

\section{A LITERATURA PARA INFÂNCIA}

Se o conceito de literatura é por si só polêmico, o que dizer então do conceito de literatura infantil? Aquela literatura cuja escrita, agenciamento e compra é feita por adultos, mas direcionada à criança. Aquela literatura cujo alijamento da "Grande Literatura" foi e ainda Ihe é frequentemente acometida.

Aquela literatura que se tem dúvidas quanto aos critérios a serem utilizados para validar ou avaliar, se critérios próprios ou critérios da "alta literatura".

A literatura infantil, apesar dos diversos estudos que têm sido realizados desde o seu surgimento, ainda constitui um terreno movediço de conceitos e debates que estimulam pesquisadores (as) a se debruçar sobre o assunto. A produção científica da área nos mostra que esta temática foi sempre debatida pelos (as) teóricos (as) no decorrer dos anos.

$\mathrm{Na}$ década de 1970, Eliana Yunes (1979) no ensaio Questões fundamentais da literatura infantil coloca algumas questões em análise acerca 
dessa tensão, como por exemplo, o fato de que nem todos os livros que são escritos para crianças são de seu agrado, e mais, muitas vezes as crianças são atraídas por livros escritos para adultos. Da mesma forma que muitos livros para a criança despertam o prazer dos adultos e isso não compromete sua maturidade intelectual. Os adultos, por sua vez, são os que escrevem e escolhem os livros, os quais nem sempre se igualam aos interesses da criança, tornando a criança impotente quanto a autonomia de decidir sobre a leitura. Além disso, os livros infantis frequentemente possuem uma preocupação com a formação didática e moral da criança.

Cunha (2004) acredita que é necessário discutir os pontos de interseção entre a literatura para crianças e a literatura para adultos. Afirma que neste caso, se o ponto de afastamento, "se der na essência do fenômeno literário, então não haverá literatura infantil". Quer dizer, "a própria expressão 'literatura infantil' torna-se absurda, pois não podemos imaginar 'literatura' sem arte" (CUNHA, 2004, p. 26).

Dessa forma, a essência literária, ou o aspecto artístico, é algo que faz parte da constituição dos dois tipos de textos. A literatura infantil, em que pese o adjetivo restritivo da expressão, tanto é mais abrangente do que comumente se imaginou, como pode ser lida e reconhecida como obra de arte pelo adulto e também para a criança (CUNHA, 2004).

Para compreender melhor alguns desses dilemas entre a relação adulto/criança na literatura infantil, é necessário retornar ao início da constituição desta literatura no cenário mundial. Conforme Zilberman e Magalhães (1987) afirmam, o surgimento da literatura infantil advém da nova concepção de infância decorrida da ascensão da família burguesa.

A atenção dada à criança no cenário familiar burguês, aliado a obrigatoriedade de seu ingresso na escola, provocaram uma aproximação entre a literatura infantil e a pedagogia, já que as histórias infantis eram criadas para se converter em instrumento desta última. De modo que esta razão lhe retirou um estatuto artístico, Ihe negando então um reconhecimento de valor estético, e, portanto, Ihe excluindo do "reduto seleto da literatura" (ZILBERMAN; MAGALHÃES, 1987, p. 4). 
Dessa forma, a pedagogização da literatura infantil, tanto impulsionou sua criação como a alijou das outras modalidades de literatura, estando ela desde seu princípio permeada de dilemas. De um lado, "o exame das suas relações com a pedagogia, a quem deve seu nascimento; e, de outro, a definição de sua capacidade estética", o que a aproxima da literatura enquanto arte (ZILBERMAN; MAGALHÃES, 1987, p .4).

Assim, tendo em vista o contexto do seu surgimento, observa-se que a didatização e escolarização do texto literário, atendia a fins moralistas e pedagógicos como uma tentativa de ser mais um instrumento de controlar 0 comportamento da criança. Isto comprometia em grande medida o potencial estético lúdico de tal literatura. Ao invés de apresentar o mundo tal qual ele é, como o faz a literatura, a pedagogização da literatura apresenta o mundo como ele deveria ser, encobrindo do texto questões inerentes à natureza humana, tais como as diferenças e conflitos existenciais (CADEMARTORI, 2010).

Tal caráter funcional da literatura, atua de modo persuasivo, redundante e fechado, não abrindo possibilidades polissêmicas, bem como questionamentos nas entrelinhas do texto. Tudo se homogeneíza na voz única no narrador, silenciando a voz do leitor (a) (CADEMARTORI, 2010). Assim retirar dos textos as contradições, a ambiguidade da vida e os conflitos e frustações da realidade, sob a suposição de que isso está protegendo a "inocência e sensibilidade da criança", representa uma falsa concepção de infância ocasionando a limitação do seu acesso ao conhecimento (YUNES, 1979).

Sendo assim, a literatura infantil termina se tornando uma nova versão de escola" não só pela linguagem empregada como pelos conceitos veiculados, onde o lugar do prazer desaparece sob a pressão dos ensinamentos (YUNES, 1979, p. 2). A autora finaliza ressaltando que é mais humano, que a

[...] realidade seja apresentada sem mistificações e possibilite 0 exercício crítico sobre a violência e a sensibilidade que coexiste, expressas quer pelo lobo comendo a vozinha, quer pelo pivete linchado pelos transeuntes da Rio Branco (YUNES, 1979, p. 15).

Todavia, Yunes e Pondé (1998, p. 132) relatam que dos anos 1970 em diante aconteceu uma renovação na literatura infantil brasileira, que "buscou alternativas para os modelos comportamentais pedagógicos e moralizantes preconizados pela literatura escolar das décadas anteriores". Por isso, 
percebemos uma alteração na concepção de criança na literatura infantil a partir da década de 1980 consistindo num movimento de resistência e crítica ao autoritarismo.

Coelho (2000), em seu compêndio de literatura infantil, ao discorrer sobre o debate que envolve a natureza específica da literatura, qual seja, uma arte literária ou uma instrução pedagógica, advoga para uma harmonia entre essas duas instâncias. Defende a autora que essa polaridade é inerente por se tratar de uma literatura que tem como foco as crianças. Assume que é importante equilibrar essas duas dimensões, não as excluindo mutuamente, mas observar essa dialética como algo natural, que busque sobretudo, retratar as mudanças existentes em nosso tempo, tendo como norte estimulação da criatividade e descoberta e a conquistas de novos valores fugindo dos padrões e mantendo sempre seu caráter de inventividade da linguagem (COELHO, 2000).

Conforme coloca Hunt (2010), as dificuldades em definir a literatura infantil advêm da própria natureza conceitual do adjetivo que lhe compõe, visto que a infância não é um conceito estável. A definição de infância se altera em razão do local e do tempo. Portanto, recomenda o autor, devemos ser muito cuidadosos (as) ao avaliar as diferentes interpretações feitas de uma obra quando ela é publicada e as análises realizadas em outros períodos com contextos sociais distintos.

Nesse sentido, ao falar de literatura infantil estamos lidando com um tema que possui múltiplas possibilidades de olhares, conceitos e ambivalências que se devem, sobretudo devido a relação entre qualidade, público e relação adulto/criança, visto que se tratam de conceitos instáveis e ao mesmo tempo complexos.

Cecília Meireles afirma que um texto se torna literário "quando o dito se coloca não apenas em função do conteúdo, mas o modo de dizer cria uma peculiaridade de graus diversos frente à linguagem do lugar comum" (MEIRELES, 2016, p. 2). Assim, o que diferencia os textos literários de textos sociológicos, filosóficos e antropológicos "é o dizer, que não se faz literal, repetitivo, mas é outro, importa-o como é dito, articulado" (YUNES, 1979, p. 3).

Sendo assim, a literatura é um convite para que os pequenos conheçam 
algo diferente e empolgante. É importante para as crianças porque propicia determinadas experiências com a linguagem e com os sentidos, que nenhuma instituição consegue oferecer da mesma forma (CADEMARTORI, 2010). A obra de arte, constituída por meio de palavras é caracterizada, conforme considera Cunha (2004), pela "abertura", isto é, pela polissemia, pela singularidade e imprevisibilidade, seja na forma ou conteúdo.

Tal literatura é primordialmente apresentada aos leitores por meio da oralidade. A oralidade constituindo a "raiz profunda" nos dizeres de Meireles, inicia o contato da criança com a poesia e a literatura, desde os primeiros anos de vida. É a primeira a penetrar na memória das pequenas e pequenos thes explicando o meio que as rodeia (MEIRELES, 2016).

Daí se tem a importância da contação de histórias e da valorização das histórias populares, tradicionais ou contos de fadas tanto para introdução da literatura aos pequenos como para a manutenção da memória coletiva (ABRAMOVICH, 1997).

Os contos tradicionais (contos de fadas, contos maravilhosos), por sua vez, são essenciais para o entendimento de si próprio e dos dilemas da vida. A fantasia reflete o mundo interior da criança com seus medos, ódios e ansiedades, indo diretamente ao encontro dos seus problemas de rejeição, conflitos edípicos, rivalidade, levando a criança a entender o mundo e sua realidade e despertando sua imaginação (YUNES, 1979; BETTELHEIM, 1980).

Essas histórias, vozes e imagens atuam no imaginário infantil contribuindo para a formação da sua personalidade e, principalmente auxiliando-a na compreensão dos seus conflitos interiores, bem como atuam no desenvolvimento linguístico dos pequenos e pequenas e na experimentação lúdica dos fonemas, frases e imagens.

Por isso, as obras adequadas ao público infantil, quer dizer, aquelas que respeitam seu público leitor são elaboradas tendo em vista a abertura que elas Ihe proporcionam, tanto em termos de texto como de som ou imagem. Ou seja, a possibilidade de atribuição de sentidos distintos, a possibilidade de fazer relações intertextuais com a realidade, conforme o repertório leitor de cada criança. 
Dessa forma, se a infância é o momento basilar da constituição do sujeito, a literatura infantil surge como um possível instrumento de formação e desenvolvimento humano. Assim, ela opera no sentido de promover uma possível superação da dependência e da carência, propiciando a autonomia do pensamento, compreensão e reformulação de conceitos (CADEMARTORI, 2010).

A relevância da literatura enquanto instrumento importante no desenvolvimento linguístico da criança, se mostra quando ela oferece ao pequeno (a) leitor (a) a experimentação lúdica dos sons da língua, facilitando assim o exercício da abstração, a associação entre letras, palavras e seu reconhecimento na vida cotidiana, quer dizer, assegura "uma relação ativa com sua língua, pelo conhecimento das potencialidades expressivas do código" (CADEMARTORI, 2010, p. 71). Por isso, estudar a linguagem sem conhecer as estruturas poético-literárias da leitura, "é como aprender a ler, escrever e interpretar, e não aprender a pensar" (DINORAH, 1995 p. 20).

Em termos da poesia para crianças, é importante estar atento a sonoridade das composições, repetição de fonemas em rimas, refrões ou ecos, além da habilidade de fazer aproximações, antes nunca pensadas, causando sentidos inesperados e dessa forma levando a criança a brincar com os sons, favorecendo a percepção da materialidade da língua (CADEMARTORI, 2010).

Nesse sentido, concordamos com Coelho (2000) quando elenca alguns pressupostos ou princípios que devem ser considerados ao lidar com a literatura infantil, a saber: concepção da criança enquanto um ser aprendiz de cultura; concepção da literatura como um fenômeno de linguagem resultante de uma experiência existencial/social/cultural; valorização das relações existentes entre literatura, história e cultura; entendimento de leitura como um diálogo entre leitor e texto como algo que envolve a globalidade das emoções e sentidos e que permite a fruição e conscientização gradativa dos valores e desvalores do convívio social; compreensão da escrita como ação ou resultado da leitura assimilada ou da criatividade estimulada pela cultura.

Outro elemento fundamental na literatura infantil é a interação entre linguagem visual e verbal que promove à criança experiências estéticas e de 
sentido com os dois códigos. Dessa forma, a relação entre texto verbal e imagem pode se dar de diversas formas e distintos graus de complexidade e de autonomia (CADEMARTORI, 2010)

Existem obras que mantêm uma congruência no diálogo entre os dois signos, obras em que a imagem extrapola o sentido do texto verbal e outras em que as duas linguagens se relacionam ironicamente, de modo que a imagem revela algo contrário ao texto verbal. A tendência atual é de valorização dos dois signos, pois tanto o texto linguístico como o texto imagético estimulam variadas percepções, reconhecimentos e interpretações da obra (CADEMARTORI, 2010). Por isso, assim como o texto escrito permite várias leituras, a ilustração deve também ser conotativa e polissêmica proporcionando à criança ir além da imagem, recriando e imaginando.

Assim, a ilustração vem ocupando um espaço privilegiado na literatura infantil, seja por meio de narrativas visuais, álbuns ilustrados ou de modo tradicional acompanhando o texto. Ela representa, da mesma forma que os outros elementos, alto potencial formador e imaginativo quando bem elaborada e pensada pelo artista que as criou.

A evidência da proximidade que a criança tem com o desenho e com a oralidade faz com que ambos elementos sejam motivo de grande interesse e de forte identificação por eles quando envolvidos em narrativas, potencializando ainda mais a característica lúdica e formadora da literatura infantil.

A escrita de livros para criança ainda continua enfrentando a ambivalência do adulto que escreve e da criança que lê, mas ainda assim, a preocupação teórico-empírica e os avanços nos estudos literários têm proporcionado o aparecimento cada vez maior de obras, escritores e ilustradores com propostas sérias com qualidade artística rica e ampla que potencializam a criatividade e inventividade da criança.

\section{CONSIDERAÇÕES FINAIS}

Como vimos, a leitura em sentido amplo é compreendida não apenas pelo ato de ler textos escritos, mas também pelo ato de ler imagens, a natureza, as pessoas. Isto quer dizer que a leitura decorre de uma interpretação e atribuição 
de sentido a algo, e sendo assim ela não deixa de ser criação. Tais significações e criações sempre partirão do contexto de fala dos leitores/receptores, ou seja, do seu lugar social, os quais envolvem questões histórias, linguísticas e ideológicas. O leitor, por sua vez, enquanto elemento fulcral do processo de leitura, atribui sentido ao texto captando o dito e o não dito e correlacionando com sua realidade.

No que se refere à literatura, é relevante citar que, conforme trouxemos, longe de ser um conceito inabalável, fixo, definitivo, é um termo imbuído de polêmicas. A valoração do que é ou não é um texto literário ou do que é ou não é um bom texto literário, é antes de tudo uma avaliação histórica, política e cultural. Por isso, assim como a questão da legibilidade do texto para Orlandi (1998) não está ligada a fatores intrínsecos ao texto, mas envolve uma historicidade e fatores contextuais de produção, a literalidade também não é inerente ao texto para Abreu (2006) e Lajolo (1982), pois a definição do que é literatura também está circundada por outros fatores, tais como questões políticas.

A literatura infantil, por seu turno, com o passar dos séculos, passou por uma renovação no que tange ao seu potencial artístico e imagético. Essa mudança se deu devido aos estudos ligados a psicologia experimental e sociologia da infância que conceberam uma nova forma de olhar a criança e a família. Tal aprimoramento interviu diretamente na maneira de lidar com a criatividade da criança e com a linguagem literária dos livros para criança, contemplando modalidades criativas em termos de formato e ideias de edição de livros.

Assim, ao ler, ver, ou ouvir literatura, a criança aciona suas habilidades interpretativas e por meio da imaginação proporcionada pela narrativa reconfigura, apreende e organiza a realidade. A apreciação estética da criança é aguçada pela fantasia, verossimilhança e poeticidade que the é apresentada na obra.

Dessa forma, o (a) contador (a) de histórias, o (a) bibliotecário (a) devem estar cientes dessa relevância para que façam parte dessa promoção da emancipação e autonomia da criança, enquanto mediadores de leitura, que por 
meio da ficção permite a ampliação de seus horizontes de expectativas e possibilitando-a a capacidade de interrogação, reflexão e criticidade perante a realidade que Ihe circunda.

Enfim, toda criança tem direito à arte, a educação e a leitura e dessa forma é de suma importância que tais obras sejam elaboradas tendo em vista as peculiaridades que envolvem a natureza da infância e os modos para se chegar até ela para tocá-la e sensibilizá-la. A leitura para a criança mais do que um modo de lazer e aquisição de saberes é uma forma de compreensão e reelaboração do mundo.

\section{REFERÊNCIAS}

ABRAMOVICH, Fanny. Literatura Infantil: gostosuras e bobices. São Paulo: Scipione, 1997.

ABREU, Márcia Azevedo de. Cultura Letrada, literatura e leitura. São Paulo: UNESP, 2006.

ALMEIDA JÚNIOR, Oswaldo. Francisco. Mediação da Informação e Múltiplas Linguagens. Tendências da Pesquisa Brasileira em Ciência da Informação, Brasília, v. 2, p. 89-103, 2009.

BETTELHEIM, Bruno. A psicanálise dos contos de fadas. Rio de Janeiro: Paz e Terra, 1980.

BORTOLIN, S.; SILVA, R. J. da. Ensino da literatura infantojuvenil na graduação e pós-graduação em ciência da informação. REBECIN, Sergipe, v.2, n.2, p.124-137, 2015.

CADEMARTORI, Lígia. O que é literatura infantil. São Paulo: Brasiliense, 2010.

CANDIDO, Antonio. Direito à Literatura. In: LIMA, A. de. et. al. O Direito à Literatura. Recife: Ed. Universitária da UFPE, 2012. p. 17-40.

CHARTIER, Roger. A aventura do livro do leitor ao navegador: conversações com Jean Lebrun. Tradução de Reginaldo Carmello Corrêa de Moraes. São Paulo: Imprensa Oficial do Estado de São Paulo, 1998.

COELHO, Nelly. Novaes. Literatura Infantil: teoria: análise: didática. São Paulo: Moderna, 2000. 
COSSON, Rildo. Círculos de leitura e letramento literário. São Paulo: Contexto, 2014.

CUNHA, Maria. Antonieta. Antunes. Literatura infantil: teoria e prática. São Paulo: Ática, 2004.

DINORAH, Maria. O Livro infantil e a formação do leitor. Petrópolis, RJ: Vozes, 1995.

FREIRE, Paulo. A importância do ato de ler: em três artigos que se completam. 51. ed. São Paulo: Cortez, 2011.

HUNT, Peter. Crítica, teoria e literatura infantil. Tradução de Cid Knipel. São Paulo: Cosacnaify, 2010.

LAJOLO, Marisa. O que é literatura. São Paulo: Brasiliense, 1982.

LIMA, Aldo. O ensino da literatura e a pedagogia do digesto. In: LIMA, A. de. et al. O Direito à Literatura. Recife: Ed. Universitária da UFPE, 2012. p. 41-54.

MARTINS, Maria. Helena. O que é leitura. São Paulo: Brasiliense, 1982.

MEIRELES, Cecília. Problemas da literatura infantil. 4. ed. São Paulo: Global, 2016.

ORLANDI, Eni Puccinelli. A polissemia da noção de leitura. In:

Discurso e leitura. São Paulo: Cortez, 1998. p. 7-12.

PETIT, Michèle. Os jovens e a leitura: uma nova perspectiva. São Paulo: Editora 34, 2008.

ROSENFELD, Anatol. Estrutura e problemas da obra literária. São Paulo: Perspectiva, 1976.

YUNES, Eliana. Questões fundamentais de literatura infantil. Rio de Janeiro: Divisão de intercâmbio e edições: PUC-Rio, 1979.

YUNES, Eliana; PONDÉ, Gloria. leitura e leituras da literatura infantil. São Paulo: FTD, 1998.

ZILBERMAN, Regina; MAGALHÃES, Ligia. Cademartori. Literatura infantil: autoritarismo e emancipação. São Paulo: Ática, 1987.

\section{READING, LITERALITY AND CHILDREN'S LITERATURE: REFLECTIONS REQUIRED FOR LIBRARIANSHIP}




\begin{abstract}
Introduction: It deals with the theoretical aspects of children's literature and the importance of the knowledge of this theme by the librarians for their performance. Objective: It seeks to understand and reflect on how the literary reading is configured in theoretical terms and what is the meaning and importance of literary language for the child. Methodology: It uses exploratory and bibliographical research to discuss the theme from the scientific and literary production of authors and critics, especially in the Brazilian context from the late 1970s to the late 2000s. Results: Presents a theoretical rescue of studies on reading, literality and children's literature demonstrating how these concepts relate to each other and emphasizing that both reading and literature are elements permeated by ideological, social and historical contexts of production. Conclusions: It concludes that children's literature operates in the development of the child's imagination and autonomy and that the librarian can contribute to the emancipation of the reader through reading mediation.
\end{abstract}

Descriptors: Reading. Literature. Literality. Children's literature.

\title{
LECTURA, LITERALIDAD Y LITERATURA INFANTIL: REFLEXIONES NECESARIAS A LA BIBLIOTECONOMÍA
}

\begin{abstract}
RESUMEN
Introducción: Trata los aspectos teóricos de la literatura infantil y la importancia del conocimiento de este tema por parte de los bibliotecarios para su desempeño. Objetivo: Busca comprender y reflexionar sobre cómo se configura la lectura literaria en términos teóricos y cuál es el significado y la importancia del lenguaje literario para el niño. Metodología: Utiliza la investigación exploratoria y bibliográfica para discutir el tema de la producción científica y literaria de autores y críticos, especialmente en el contexto brasileño desde finales de los años setenta hasta finales de los años 2000. Resultados: Presenta un rescate teórico de estudios sobre lectura, literalidad y literatura infantil que demuestra cómo estos conceptos se relacionan entre sí y enfatiza que tanto la lectura como la literatura son elementos impregnados por contextos de producción ideológicos, sociales e históricos. Conclusiones: Concluye que la literatura infantil opera en el desarrollo de la imaginación y autonomía del niño y que el bibliotecario puede contribuir a la emancipación del lector a través de la mediación lectora.
\end{abstract}

Descriptores: Lectura. La literatura. Literalidad. Literatura Infantil. Biblioteconomía.

Recebido em: 29/09/2019

Aceito em: 22/11/2019 